\title{
Inoculação de Sclerotinia sclerotiorum em sementes de oleaginosas: transmissão e seus efeitos sobre a emergência de plantas
}

\author{
Inoculation of Sclerotinia sclerotiorum in seed of \\ oleaginous plants: transmission and effects on emergence

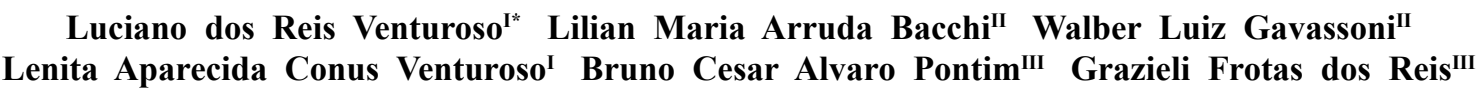

RESUMO

O trabalho propôs-se a verificar a transmissibilidade de Sclerotinia sclerotiorum de sementes de canola, cártamo, crambe, girassol, nabo forrageiro e níger inoculadas artificialmente e suas implicações na emergência de plântulas. $O$ isolado fúngico foi repicado em placas de Petri, contendo meio BDA, incubado a $20^{\circ} \mathrm{C}$ e fotoperiodo de 12 horas. Após o crescimento do patógeno, foram colocadas 50 sementes de cada cultura por placa, onde permaneceram por 20 horas. Como testemunha, utilizaram-se sementes incubadas nas mesmas condições, porém apenas em meio BDA. Observou-se que $\boldsymbol{S}$. sclerotiorum pode ser transmitido para as plântulas das culturas quando associado às suas sementes, sendo estas uma importante fonte de inóculo. O fungo provocou tombamento depréepós-emergência em todas as espécies estudadas.

Palavras-chave: transmissão semente-plântula, fonte de inóculo, plantas oleaginosas.

\section{ABSTRACT}

The study aimed to verify the transmission of Sclerotinia sclerotiorum of rapeseed, safflower, crambe, sunflower, radish and niger seed (artificially inoculated) and its implications on seedling emergence. The fungal isolate was peaked in Petri dishes containing PDA medium and incubated at $20^{\circ} \mathrm{C}$ and 12 hours photoperiod. After the growth of the pathogen, 50 seeds were placed on each plate cultures where they remained for 20 hours. As a control we used seeds incubated under the same conditions, but only on PDA. It was observed that S. sclerotiorum can be transmitted to seedlings of crops when associated with its seeds, being an important source of inoculum. The fungus caused damping-off in all of the studied species.

Key words: transmission seed-seedling, source of inoculum, oleaginous plants.

\section{INTRODUÇÃO}

A implantação do Programa de Biodiesel no Brasil, que determina a adição crescente de óleos de origem vegetal ao diesel, serviu como incentivo à produção de várias culturas, particularmente as oleaginosas (SILVA \& FREITAS, 2008). As espécies mais cultivadas para produção de biodiesel no país são: algodão, amendoim, canola, crambe, girassol, soja, dendê, mamona e pinhão manso (TRZECIAK et al., 2008), todavia, muitas dessas espécies, têm sido comercializadas e cultivadas, sem que sejam realizados testes ou fiscalizações que atestem padrões mínimos de qualidade destinados à produção de sementes, o que torna frequente a ocorrência de problemas relacionados à qualidade fisiológica e sanitária das sementes.

Para TEIXEIRA \& MACHADO (2003), a presença de patógenos em sementes relacionase diretamente à baixa germinação, vigor e deterioração, uma vez que a maioria dos patógenos pode ser transmitida à progênie, causando prejuízos econômicos aos produtores. Todavia, MARINO et al. (2008) salientam que a constatação de microorganismos na semente, mesmo patogênicos, não é suficiente para garantir a infecção da planta proveniente dessa semente, pois vários fatores influenciam em sua transmissão.

A expansão das culturas, associada à falta de cuidados fitossanitários, como o uso de sementes

\footnotetext{
Instituto Federal de Rondônia (IFRO), Campus Ariquemes, Rodovia RO-257, km 13, CP 130, 76870-970, Ariquemes, RO, Brasil. E-mail: luciano.venturoso@ifro.edu.br.*Autor para correspondência.

IIFaculdade de Ciências Agrárias (FCA), Universidade Federal da Grande Dourados (UFGD), Dourados, MS, Brasil.

IIIPrograma de Pós-graduação em Agronomia, UFGD, Dourados, MS, Brasil.
} 
infectadas, além dos danos diretos ocasionados às sementes, também desempenha importante papel na disseminação de patógenos, constituindo-se em um meio de sobrevivência do patógeno em contato direto com o hospedeiro e assegurando sua introdução já nos primeiros estágios de desenvolvimento da planta (SANTOS et al., 1996).

Entre os patógenos disseminados por sementes, destaca-se o fungo $\boldsymbol{S}$. sclerotiorum, agente causal da doença conhecida como mofo branco. Este patógeno pode ser transmitido, associado às sementes na forma de micélio dormente ou acompanhando o lote por meio de estruturas de resistência, chamadas escleródios (KAWASAKI \& MACHADO, 2013). Infecção de sementes tem sido relatada em alguns hospedeiros, os quais incluem girassol, soja e feijão (GOMES et al., 2006; HENNEBERG et al., 2012; BOTELHO et al., 2013).

A curtas distâncias $\boldsymbol{S}$. sclerotiorum pode ser disseminado por meio da ejeção de ascósporos, como demonstrado por BEN-YEPHET \& BITTON (1985), os quais relataram que até $90 \%$ dos ascósporos liberados a partir de apotécios do patógeno permanecem em uma faixa de apenas 100 metros da fonte de inóculo. No entanto, o principal responsável pela disseminação do fungo a longas distâncias tem sido o uso de sementes infectadas, sendo este o meio mais comum para introdução da doença em áreas indenes (BOTELHO et al., 2013).

O bom desempenho de uma cultura depende da qualidade das suas sementes, pois elas contêm todo o potencial genético que a planta pode expressar (MENEZES et al., 2011). O uso de sementes de qualidade e dentro dos padrões sanitários está entre as melhores estratégias para diminuir a disseminação de patógenos. Nesse sentido, esteve em consulta pública, pelo Ministério da Agricultura, na Portaria no 47, de 26 de fevereiro de 2009 (Diário Oficial 40, seção 1 , pág. 10 e 11 de 02/03/2009), o padrão zero para $\boldsymbol{S}$. sclerotiorum em sementes de feijão, soja e girassol, não podendo haver nenhum escleródio no exame da amostra de sementes secas, todavia, o texto não menciona a infecção de sementes por micélio fúngico, outro inóculo com potencial para transmissão da doença. Em estudos com soja, TELES et al. (2013) destacaram que as etapas do beneficiamento eliminam os escleródios de $\boldsymbol{S}$. sclerotiorum das sementes, no entanto, sementes infectadas por micélio não foram eliminadas, tornando-se possíveis fontes de inóculo no campo.

No Brasil, tem-se verificado a preocupação com relação à infecção das sementes por micélio de S. sclerotiorum (HENNEBERG et al., 2012;
BOTELHO et al., 2013; TELES et al., 2013), todavia, a taxa de transmissão do patógeno, para muitos de seus hospedeiros, ainda não foi quantificada, tampouco, tem-se relacionado a infecção fúngica com o vigor de sementes e desenvolvimento de plantas. Diante do contexto, o trabalho propôs-se a verificar a transmissibilidade de $\boldsymbol{S}$. sclerotiorum a partir de sementes de canola, cártamo, crambe, girassol, nabo forrageiro e níger, inoculadas artificialmente, às suas plântulas, assim como avaliar a sua relação e implicação sobre a emergência de plântulas.

\section{MATERIAL E MÉTODOS}

Escleródios de $\boldsymbol{S}$. sclerotiorum coletados em lavoura de soja foram submetidos à assepsia em álcool $50 \%$ e hipoclorito de sódio a $1 \%$, ambos por um minuto, lavados com água destilada e esterilizada, e secos em câmara de fluxo de ar. Posteriormente, foram acondicionados em placas de Petri contendo meio de batata-dextrose-ágar (BDA) e incubados à $20^{\circ} \mathrm{C}$ e fotoperíodo de 12 horas por sete dias. Para produção dos escleródios, dez discos de $0,9 \mathrm{~cm}$ de diâmetro colonizados com micélio do patógeno foram depositados sobre o substrato de cenoura cortada em rodela e incubados a $20^{\circ} \mathrm{C}\left( \pm 2^{\circ} \mathrm{C}\right)$ sob escuro contínuo, permanecendo nestas condições até a formação dos escleródios.

Os escleródios produzidos foram repicados em placas de Petri, contendo meio BDA, as quais foram vedadas com filme plástico e incubadas em BOD a $20^{\circ} \mathrm{C}\left( \pm 2^{\circ} \mathrm{C}\right)$ de temperatura e fotoperíodo de 12 horas, para promover a colonização do meio de cultura pelo patógeno. Depois do crescimento do patógeno, 50 sementes de cada cultura, canola (Brassica napus var. oleifera), cártamo (Carthamus tinctorius), crambe (Crambe abssynica), girassol (Helianthus annuus), nabo forrageiro (Raphanus sativus var. oleiferus) e níger (Guizotia abyssinica), previamente desinfestadas, como mencionado para os escleródios, foram depositadas em camada única e levemente pressionadas sobre o meio colonizado, onde permaneceram por um período de 20 horas. Como testemunha, utilizaram-se sementes incubadas nas mesmas condições, porém, apenas em meio BDA. Foi adotado o delineamento experimental inteiramente casualizado, em arranjo fatorial $6 \times 2$, com quatro repetições.

$\mathrm{O}$ ensaio foi conduzido em sala climatizada, temperatura de $24^{\circ} \mathrm{C}\left( \pm 1^{\circ} \mathrm{C}\right)$, umidade de $70 \%$ e luminosidade média de 10000 lux. Foram semeadas 200 sementes por tratamento em bandejas contendo $8,5 \mathrm{dm}^{3}$ de solo peneirado, do tipo Latossolo 
Vermelho Distroférrico, coletado em área não cultivada. O solo foi irrigado, mantendo-se turno de rega de dois dias, de modo a manter a umidade do solo em $60 \%$ da capacidade de campo.

A patogenicidade do fungo às culturas foi analisada por meio da quantificação, aos quinze dias após a semeadura, do índice de velocidade de emergência (IVE) e do percentual de emergência e tombamento de plântulas. Foi considerada como emergida a semente que demonstrou sua aptidão em produzir uma planta normal sob condições de campo (BRASIL, 2009). O IVE foi calculado pelo somatório dos quocientes resultantes entre o número total de plantas emergidas a cada dia e o número de dias decorridos da semeadura. O percentual de tombamento foi mensurado contando-se o número de plântulas tombadas com ou sem a presença de micélio fúngico em relação ao número de plântulas emergidas.

Para avaliação da transmissibilidade do patógeno via sementes, foram coletadas quinze sementes não emergidas, quinze plântulas tombadas e quinze plântulas assintomáticas, lavadas em água correntepararetiradadosoloaderidoaelasesubmetidas à assepsia em álcool $50 \%$ e hipoclorito de sódio a $1 \%$ por um minuto, sendo posteriormente lavadas com água destilada e esterilizada. Os fragmentos vegetais foram plaqueados em meio Neon (STEADMAN et al., 1994). As placas foram incubadas a $20^{\circ} \mathrm{C}\left( \pm 2^{\circ} \mathrm{C}\right)$, fotoperíodo de 12 horas e intensidade luminosa de 1350lux, até a mudança da cor do meio de azul para amarelo. $\mathrm{O}$ número de plântulas assintomáticas de crambe, e tombadas de crambe e cártamo foram inferiores aos valores previamente estabelecidos para realização do teste Neon, sendo utilizada, nestes casos, a quantidade de material disponível.

Os dados foram submetidos à análise de variância com o programa SISVAR, e as médias comparadas pelo teste de agrupamento de ScottKnott a 5\% de probabilidade.

\section{RESULTADOS E DISCUSSÃO}

Foi verificada interação significativa entre os fatores para as análises de emergência e IVE. As culturas diferiram no percentual de emergência, em ambas as situações, quando inoculadas com o fungo como também para àquelas não submetidas à inoculação (Tabela 1). Torna-se importante salientar a significativa redução na emergência das plantas de níger, nabo forrageiro, girassol, cártamo e crambe inoculadas com $\boldsymbol{S}$. sclerotiorum, destacando-se as quatro últimas, que apresentaram redução superior a $60 \%$ na emergência de plantas.

$O$ fungo causou a morte de sementes de todas as culturas estudadas, mesmo antes de iniciarem o processo germinativo, fato que pode estar associado à agressividade e condições favoráveis ao patógeno. A maior quantidade de sementes mortas foi verificada em crambe, constatando-se apenas $4,4 \%$ de emergência para as sementes inoculadas. Semelhantemente ao ocorrido neste trabalho, BOTELHO et al. (2013) verificaram redução na germinação de sementes de feijão inoculadas com S. sclerotiorum, enquanto MUELLER et al. (1999), observaram que a maioria das sementes de soja infectadas com o fungo nem chegaram a germinar.

Deve-se enfatizar que, mesmo proporcionando condições adequadas ao crescimento e desenvolvimento de $\boldsymbol{S}$. sclerotiorum, a cultura de canola não apresentou redução significativa na emergência de plantas. Não se pode afirmar que o fato esteja relacionado a algum mecanismo de defesa das plantas de canola, como demonstrado por GARG et al. (2010) ou mesmo ao período latente do patógeno,

Tabela 1 - Percentual de emergência, índice de velocidade de emergência (IVE) e percentual de redução em relação à testemunha não inoculada (SI) de espécies oleaginosas submetidas à inoculação artificial com o fungo Sclerotinia sclerotiorum.

\begin{tabular}{|c|c|c|c|c|c|c|}
\hline \multirow{2}{*}{ Culturas } & \multicolumn{2}{|c|}{------ Emergência (\%) ------ } & \multirow{2}{*}{ Percentual de redução } & \multicolumn{2}{|c|}{-------------- IVE --------------- } & \multirow{2}{*}{ Percentual de redução } \\
\hline & SI & INOC & & SI & INOC & \\
\hline Canola & $98,0 \mathrm{~A} \mathrm{a}$ & $77,0 \mathrm{~A} \mathrm{a}$ & 21,4 & $11,8 \mathrm{~A} \mathrm{a}$ & $10,6 \mathrm{~A} \mathrm{a}$ & 10,2 \\
\hline Níger & $96,1 \mathrm{~A} \mathrm{a}$ & $63,2 \mathrm{~B}$ a & 34,2 & $13,1 \mathrm{~A} \mathrm{a}$ & $8,8 \mathrm{~B} \mathrm{a}$ & 32,8 \\
\hline Nabo F. & $98,0 \mathrm{~A} \mathrm{a}$ & $34,3 \mathrm{~B} \mathrm{~b}$ & 65,0 & $12,6 \mathrm{~A} \mathrm{a}$ & $10,3 \mathrm{~A} \mathrm{a}$ & 18,3 \\
\hline Girassol & $74,0 \mathrm{~A} \mathrm{~b}$ & $25,0 \mathrm{~B} \mathrm{~b}$ & 66,2 & $8,4 \mathrm{~A} \mathrm{c}$ & $3,9 \mathrm{~B} \mathrm{~b}$ & 53,6 \\
\hline Crambe & $79,4 \mathrm{~A} \mathrm{~b}$ & $4,4 \mathrm{~B} \mathrm{c}$ & 94,5 & $9,9 \mathrm{~A} \mathrm{~b}$ & $0,7 \mathrm{~B} \mathrm{~d}$ & 92,9 \\
\hline Cártamo & $58,3 \mathrm{~A} \mathrm{c}$ & $11,8 \mathrm{~B} \mathrm{c}$ & 79,8 & $7,0 \mathrm{~A} \mathrm{c}$ & $1,9 \mathrm{~B} \mathrm{c}$ & 72,9 \\
\hline $\mathrm{CV}(\%)$ & \multicolumn{2}{|c|}{11,27} & \multicolumn{3}{|c|}{7,58} & \\
\hline
\end{tabular}

Médias seguidas pela mesma letra, maiúscula na linha e minúscula na coluna, não diferem entre si pelo teste de agrupamento Scott-Knott a $5 \%$ de probabilidade. 
porém, de acordo com BOTELHO et al. (2013), a agressividade do patógeno pode estar relacionada com o tempo de contato com o hospedeiro. Os autores, em trabalhos com inoculação de dois isolados de $\boldsymbol{S}$. sclerotiorum, em sementes de feijão, observaram que um dos isolados, após 36 horas em contato com as sementes, não reduziu o estande final de plantas, no entanto, quando estas permaneceram em contato com o mesmo isolado por 72 horas, houve redução no estande de $71,4 \%$. Mesmo que a associação de fungos com as sementes não acarrete em queda na qualidade fisiológica, esta associação pode favorecer a sobrevivência e disseminação do patógeno.

As culturas de canola, níger e nabo forrageiro apresentaram os maiores índices de velocidade de emergência, tanto para as inoculadas como para as que não tiveram contato com o patógeno. No entanto, assim como ocorreu para as plantas de girassol, crambe e cártamo, também níger teve sua velocidade de emergência afetada por $\boldsymbol{S}$. sclerotiorum. Todavia, a maior redução, $92,9 \%$, foi verificada na cultura do crambe. Foi constatada correlação linear positiva e significativa entre o percentual de redução do IVE e da emergência, podendo-se inferir que a menor velocidade de germinação possibilitou maior tempo de contato entre semente e patógeno, aliado ao fato de sementes liberarem certas quantidades de açúcares com o atraso da germinação, favorecendo a infecção pelo patógeno e a consequente redução na capacidade germinativa das sementes. Resultados semelhantes foram relatados por BOTELHO et al. (2013), que verificaram redução gradativa no percentual de emergência e índice de velocidade de emergência com o aumento do tempo de exposição de sementes de feijão à $\boldsymbol{S}$. sclerotiorum.

O fungo provocou tombamento de pré e pósemergência em todas as culturas analisadas (Figura 1), porém, destaca-se o elevado percentual de tombamento de pós-emergência nas plântulas de nabo forrageiro, provavelmente, associado à alta velocidade com que as plântulas da cultura emergiram, fazendo com que o ataque do patógeno fosse direcionado, principalmente, ao colo das plântulas inoculadas após sua emergência.

Comportamento semelhante, porém em menor intensidade, foi verificado para as culturas da canola, girassol eníger, com percentual de tombamento de $15,2,10,8$ e $8,8 \%$, respectivamente. Para o girassol, em particular, vale salientar um fato interessante, apesar de comum em muitas dicotiledôneas, onde as plântulas emergiram e permaneceram com o tegumento da semente aderida aos cotilédones, promovendo, desta forma, a transmissão via tegumento-cotilédone após a emergência, o que se poderia denominar de transmissão cotiledonar. Em soja, tem sido relatado que $\boldsymbol{S}$. sclerotiorum utiliza justamente os cotilédones como fonte de energia para produção de novos escleródios (YANG et al., 1998).

$\mathrm{Na}$ cultura do crambe, foi observado tombamento de plântulas em sementes não inoculadas. As referidas plântulas foram colocadas em câmara úmida, sendo constatada a presença do fungo Alternaria sp. Em ensaios preliminares, também foi verificada a

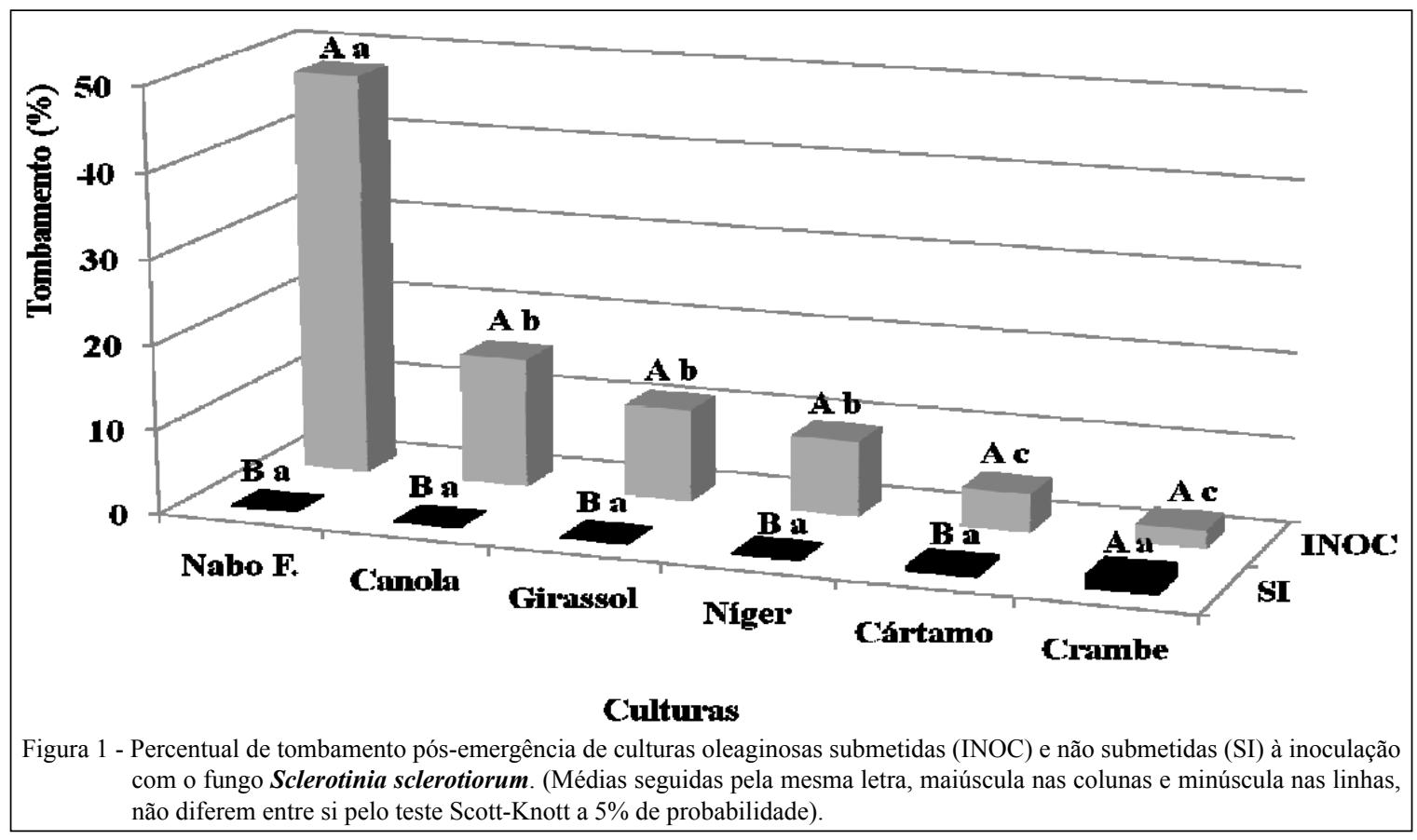

Ciência Rural, v.45, n.5, mai, 2015. 
associação do fungo às sementes de crambe e cártamo, provocando tombamento em ambas as culturas.

A patogenicidade do fungo associado às sementes e plântulas foi comprovada por meio do teste Neon, evidenciado pela detecção do patógeno em todas as sementes e plântulas sintomáticas plaqueadas sobre o meio de cultura (Tabela 2). O teste revelou que o patógeno pode ser transmitido para as plântulas das culturas quando associado às suas sementes, sendo uma importante fonte de inóculo em condições favoráveis ao patógeno. A transmissão de $\boldsymbol{S}$. sclerotiorum via sementes também foi verificada em soja (HENNEBERG et al., 2012) e feijão (BOTELHO et al., 2013).

Sclerotinia sclerotiorum é considerado um patógeno extremamente agressivo, conhecido por colonizar rapidamente o tecido vegetal e causar a morte da planta. Em virtude desse fato e aliado às condições climáticas favoráveis ao patógeno, no interior da sala climatizada, e os tecidos tenros das plântulas, não se esperava constatar infecção do fungo em plantas assintomáticas, como verificado para girassol e níger. Não foi encontrado na literatura outro relato de que S. sclerotiorum pode apresentar infecção latente. Por ocasião da coleta das sementes para realização do teste Neon, constatou-se a presença de pequenos escleródios $(<0,01 \mathrm{~g})$ aderidos às sementes não germinadas das culturas. De acordo com VENTUROSO et al. (2014), escleródios com massa inferior a $0,01 \mathrm{~g}$, localizados na superfície do solo, representam menor potencial infectivo, todavia, ainda assim, podem liberar ascósporos e causar doença, o que representaria risco às culturas subsequentes. Corroborando os resultados, tem sido relatada produção de escleródios no solo a partir de sementes de soja (YANG et al., 1998), sejam elas inoculadas artificialmente ou não (HENNEBERG et al., 2012).

Tabela 2 - Detecção de Sclerotinia sclerotiorum, inoculado artificialmente, em sementes e plântulas de culturas oleaginosas, coletadas quinze dias após a semeadura.

\begin{tabular}{lccc}
\hline Culturas & $\begin{array}{c}\text { Percentual de } \\
\text { sementes } \\
\text { infectadas (N } \\
\text { sementes } \\
\text { coletadas) }\end{array}$ & $\begin{array}{c}\text { Percentual de } \\
\text { plântulas } \\
\text { tombadas (N } \\
\text { coletado) }\end{array}$ & $\begin{array}{c}\text { Percentual de } \\
\text { plântulas } \\
\text { assintomáticas } \\
\text { infectadas (N } \\
\text { coletado) }\end{array}$ \\
\hline Canola & $100(15)$ & $100(15)$ & $0(15)$ \\
Cártamo & $100(15)$ & $100(9)$ & $0(15)$ \\
Crambe & $100(15)$ & $100(4)$ & $0(9)$ \\
Girassol & $100(15)$ & $100(15)$ & $13,3(15)$ \\
Nabo F. & $100(15)$ & $100(15)$ & $0(15)$ \\
Niger & $100(15)$ & $100(15)$ & $6,7(15)$ \\
\hline
\end{tabular}

MUELLER et al. (1999) verificaram, por duas safras consecutivas, em sementes de soja, a produção de escleródios e, nas duas oportunidades observaram germinação carpogênica, sem, contudo, constatarem infecção das plantas na mesma temporada. Para NAPOLEÃO et al. (2005), o maior problema em se permitir o aumento da doença é justamente o fato de se aumentar o inóculo para os cultivos subsequentes, o que afetaria a sustentabilidade do sistema de produção em curto prazo.

Os resultados obtidos neste trabalho demonstram a possibilidade de $\boldsymbol{S}$. sclerotiorum, quando inoculado nas sementes de canola, cártamo, crambe, girassol, nabo forrageiro e níger, ser transmitido às plântulas de forma eficiente. HENNEBERG et al. (2011) concluíram que sementes de soja também podem transmitir o fungo às suas plantas, aumentando o potencial de inóculo da doença no campo. Os resultados sugerem que a doença, mofo branco, pode ser introduzida em áreas indenes por meio de sementes infectadas, devendo-se, portanto, dar maior enfoque a testes rápidos e eficientes que venham a identificar sementes infectadas e não apenas a infestação promovida por escleródios. Pelos resultados encontrados no trabalho, sugere-se, ainda, que outros testes sejam incluídos na constatação do patógeno e a ampliação do padrão zero de $\boldsymbol{S}$. sclerotiorum para outros hospedeiros e não apenas nos lotes de sementes de girassol, soja e feijão.

\section{CONCLUSÃO}

Constatou-se a transmissibilidade de Sclerotinia sclerotiorum via sementes inoculadas às plântulas das culturas de canola, cártamo, crambe, girassol, nabo forrageiro e níger. Sclerotinia sclerotiorum associado às sementes reduz 0 percentual e a velocidade de emergência das culturas de cártamo, crambe, girassol, nabo forrageiro e níger.

\section{AGRADECIMENTOS}

A Coordenação de Aperfeiçoamento de Pessoal de Nível Superior (CAPES) pela concessão da bolsa ao primeiro autor.

\section{REFERÊNCIAS}

BEN-YEPHET, Y.; BITTON, S. Use of a selective medium to study the dispersal of ascospores of Sclerotinia sclerotiorum. Phytoparasitica, v.13, n.1, p.33-40, 1985. Disponível em: <http:// link.springer.com/article/10.1007\%2FBF02994435>. Acesso em: 05 mar. 2014.

BOTELHO, L.S. et al. Performance of common bean seeds infected by the fungus Sclerotinia sclerotiorum. Journal of Seed 
Science, v.35, n.2, p.153-160, 2013. Disponível em: <http://www. scielo.br/pdf/jss/v35n2/03.pdf>. Acesso em: 08 jul. 2014. doi: $10.1590 /$ S2317-15372013000200003.

BRASIL. Ministério da Agricultura, Pecuária e Abastecimento. Secretaria de Defesa Agropecuária. Regras para análise de sementes. Brasília: MAPA/ACS, 2009. 399p.

GARG, H. et al. The infection processes of Sclerotinia sclerotiorum in cotyledon tissue of a resistant and a susceptible genotype of Brassica napus. Annals of Botany, v.106, n.6, p.897-908, 2010. Disponível em: <http://aob.oxfordjournals.org > Acesso em: 22 jul. 2014. doi:10.1093/aob/mcq196.

GOMES, D.P. et al. Qualidade fisiológica e sanitária de sementes de girassol produzidas na região de Timon, Maranhão. Summa Phytopathologica, v.32, n.3, p.291-292, 2006. Disponível em: $<$ http://www.scielo.br/pdf/sp/v32n3/a16v32n3.pdf >. Acesso em: 05 mar. 2014. doi: 10.1590/S0100-54052006000300016.

HENNEBERG, L. et al. Efficiency of methods to detect Sclerotinia sclerotiorum in commercial soybean seed lots. Revista Brasileira de Sementes, v.34, n.1, p.61-69, 2012. Disponível em: <http:// www.scielo.br/pdf/rbs/v34n1/a08v34n1.pdf>. Acesso em: 08 jul. 2014. doi: 10.1590/S0101-31222012000100008.

HENNEBERG, L. et al. Importância da detecção de Sclerotinia sclerotiorum em sementes de soja. Informativo Abrates, v.21, n.3, p.41-46, 2011. Disponível em: <http://www.abrates.org.br/ portal/images/stories/informativos/v21n3/artigo04.pdf $>$. Acesso em: 05 mar. 2014.

KAWASAKI, V.H.; MACHADO, J.C. Establishment of a semiselective method for the detection of Sclerotinia sclerotiorum in dry bean and soybean seeds. Journal of Seed Science, v.35, n.4, p.435-442, 2013. Disponível em: <http://www.scielo.br/pdf/ jss/v35n4/04.pdf>. Acesso em: 08 jul. 2014. doi: 10.1590/S231715372013000400004.

MARINO, R.H. et al. Incidência de fungos em sementes de Phaseolus vulgaris L. provenientes do Estado de Sergipe. Revista Brasileira de Ciências Agrárias, v.3, n.1, p.26-30, 2008. Disponível em: <http://www.redalyc.org/pdf/1190/119017261005. pdf>. Acesso em: 05 mar. 2014.

MENEZES, V.O. et al. Detecção e influência de Fusarium spp. na qualidade fisiológica de sementes de pepino. Ciência Rural, v.41, n.2, p.193-199, 2011. Disponível em: <http://www.scielo. br/pdf/cr/v41n2/a855cr3557.pdf > . Acesso em: 05 mar. 2014. doi: $10.1590 / \mathrm{S} 0103-84782011005000006$.

MUELLER, D.S. et al. Development of sclerotia and apothecia of Sclerotinia sclerotiorum from infected soybean seed and its control by fungicide seed treatment. Plant Disease, v.83, n.12, p.1113 1115, 1999. Disponível em: <http://apsjournals.apsnet.org/doi/ pdf/10.1094/PDIS.1999.83.12.1113>. Acesso em: 05 mar. 2014.
NAPOLEÃO, R. et al. Intensidade do mofo-branco do feijoeiro em plantio convencional e direto sob diferentes lâminas d'água. Fitopatologia Brasileira, v.30, n.4, p.374-379, 2005. Disponível em: <http://www.scielo.br/pdf/fb/v30n4/a06v30n4.pdf >. Acesso em: 05 mar. 2014. doi: 10.1590/S0100-41582005000400006.

SANTOS, G.R. et al. Transporte, transmissibilidade e patogenicidade da microflora associada às sementes de feijão (Phaseolus vulgaris L.). Revista Ceres, v.43, n.249, p.621-627, 1996. Disponível em: <http://www.ceres.ufv.br/ceres/revistas/ V43N249P04996.pdf>. Acesso em: 05 mar. 2014.

SILVA, P.R.F.; FREITAS, T.F.S. Biodiesel: o ônus e o bônus de produzir combustível. Ciência Rural, v.38, n.3, p.843-851, 2008. Disponível em: <http://www.scielo.br/pdf/cr/v38n3/ a44v38n3.pdf $>$. Acesso em: 08 jul. 2014. doi: 10.1590/S010384782008000300044

STEADMAN, J.R. et al. Semi-selective medium for isolation of Sclerotinia sclerotiorum. Canadian Journal of Plant Pathology, v.16, n.1, p.68-70, 1994. Disponível em: <http://www.tandfonline.com/doi/ pdf/10.1080/07060669409500791>. Acesso em: 05 mar. 2014.

TEIXEIRA, H.; MACHADO, J.C. Transmissibilidade e efeito de Acremonium strictum em sementes de milho. Ciência e Agrotecnologia, v.27, n.5, p.1045-1052, 2003. Disponível em: $<$ http://www.scielo.br/pdf/cagro/v27n5/a11v27n5.pdf>. Acesso em: 05 mar. 2014. doi: 10.1590/S1413-70542003000500011.

TELES, H.F. et al. Incidence of Sclerotinia sclerotiorum and the physical and physiological quality of soybean seeds based on processing stages. Journal of Seed Science, v.35, n.4, p.409-418, 2013. Disponível em: <http://www.scielo.br/pdf/jss/ v35n4/01.pdf>. Acesso em: 08 jul. 2014. doi: 10.1590/S231715372013000400001

TRZECIAK, M.B. et al. Utilização de sementes de espécies oleaginosas para produção de biodiesel. Informativo Abrates, v.18, n.1,2,3, p.30-38, 2008. Disponível em: <http://www.ufvjm. edu.br/disciplinas/agr011/files/2013/10/Biodiesel.pdf>. Acesso em: 08 jul. 2014.

VENTUROSO, L.R. et al. Relação de massa e localização do escleródio no solo com germinação carpogênica de Sclerotinia sclerotiorum. Summa Phytopathologica, v.40, n.1, p.29-33, 2014. Disponível em: <http://www.scielo.br/pdf/sp/v40n1/ v40n1a04.pdf>. Acesso em: 16 mar. 2014. doi: 10.1590/S010054052014000100004.

YANG, X.B. et al. First report of sclerotium production by Sclerotinia sclerotiorum in soil on infected soybean seeds. Plant Disease, v.82, n.2, p.264, 1998. Disponível em: <http://apsjournals. apsnet.org/doi/abs/10.1094/PDIS.1998.82.2.264B>. Acesso em: 05 mar. 2014 